\title{
Pickling Inhibitor to Electroplating: A Plant Extract
}

\author{
Meenakshi. R. \\ Associate Professor, Department of Chemistry, NGM College, Pollachi, \\ Tamilnadu, India \\ mmvmeenakshi2012@gmail.com
}

\begin{abstract}
Electroplating of any metal or alloy requires cleansing to remove dirt's, earthen particles, and/ or corrosion products on the surface by immersing the metal or alloy in acid pickling baths which results in metal dissolution with copious evolution of hydrogen fumes. In the present study, Leaves extract of the plant, Hyptis suaveolens (HYP) was investigated as pickling inhibitor. Tests were conducted with rusted iron plates, collected from local electroplating industry by immersing them in hydrochloric acid without and with $10 \%(\mathrm{v} / \mathrm{v})$ of plant extract. The weights of the plates were taken before and after pickling in commercial hydrochloric acid with and without plant extract. It was found that the weight loss of the plate immersed in acid containing plant extract was lesser compared to that in acid without extract. Both the pickled plates were then subjected to electroplating. Better deposition of nickel and chromium metals from electroplating baths on the plate pickled in acid containing plant inhibitor with weight increase; substantiate the benefit of using the plant extract in pickling bath investigated.
\end{abstract}

Keywords: Pickling inhibitor, electroplating

\section{INTRODUCTION}

Metals are noted for illustrious properties such as tensile strengths, ductility, malleability, electrical conductivity and hence find wide use in all fields. The metal is extracted from its ore and then is subjected to fabrication and /or electroplating. Before fabrication and / or electroplating, it needs cleansing to remove dirt's, earthen particles, and/ or corrosion products on the surface by immersing the metal in pickling baths. In pickling baths either commercial hydrochloric or sulphuric acid is used $^{1}$.

The metal reacts with the acid in great affinity; consequently corrosion products, dirts etc, are removed, some amount of metal is converted into its compound, and hence its advantageous metallic properties are lost. We call it as base metal loss or corrosion, which cost more than billion dollars towards replacement, repair and maintenance.

During pickling process, metal (for example Fe) reacts with the acid vigorously, with massive liberation of injurious hydrogen gas according to the equation (1):

$\mathrm{Fe}+2 \mathrm{HCl} \longrightarrow \mathrm{Fe}^{2+}+\mathrm{H}_{2}+2 \mathrm{Cl}^{-}$

Then the pickled metal needs immediate treatment such as fabrication and / or electroplating. Delaying is sometimes unavoidable. In such situation, the metal has to be pickled again, which results in further dissolution of base metal. Enhancement of corrosion resistance during pickling (reduction of metal dissolution) could be done by using corrosion inhibitors. Inhibitors are chemicals, organic or inorganic in nature ${ }^{2}$. While a small quantity is added to the pickling bath, the inhibitor minimizes both the metal dissolution and hydrogen evolution besides enhancing corrosion resistance. Use of pickling inhibitors in the corrosive environment reduces metal loss either by forming protective film or passivating Natural plants extracts ${ }^{3-6}$ being cheap, easily available, economical and providing weed free surrounding, requiring no formal education for the preparation, could find wider application as pickling inhibitors.

In the present study, leaves extract of the plant, Hyptis suaveolens is investigated as pickling inhibitor. Weights of pickled iron plates with and without plant extract and weights of electroplated plates were taken to reveal the corrosion inhibitive effect of the studied plant extract. 


\section{EXPERIMENTAL /METHODS AND MATERIALS}

\subsection{Preparation of Plant Extract}

One kg of fresh leaves of Hyptis suaveolens was shade dried and powdered. Extract of the leaves was prepared by refluxing $100 \mathrm{~g}$ of powder in $1 \mathrm{~L}$ of $1 \mathrm{M} \mathrm{HCl}$ for $3 \mathrm{~h}$ using heating mantle, set up to $30^{\circ} \mathrm{C}$. Kept over night and then filtered. The filtrate was used as plant extract.

\subsection{Metal Samples Used}

Two rusted iron plates (A\&B) were collected from local electroplating industry, namely Arul Jothi, Metal Coatings, Specialists in Plating,51, Sundara Bilas, Ginning Factory Campus, Opposite to Black Mariyamman Kovil, Udumalai Road, Pollachi,Tamil Nadu, India.

Corroded plates were weighed using Shimatzu Electronic balance.

Weight of corroded metal plate, $\mathrm{A}=34.5727 \mathrm{~g}$

Weight of corroded metal plate, $\mathrm{B}=34.7488 \mathrm{~g}$

Then the metal plate, A, was pickled to remove dirt and corrosion products on the surface using 100 $\mathrm{ml}$ of commercial hydrochloric acid. That is, immersed for 15 minutes and taken out, washed thoroughly with water, dried the pickled plate in open air.

The metal plate, B ,was pickled to remove dirt and corrosion products using $90 \mathrm{ml}$ of commercial hydrochloric acid and $10 \mathrm{ml}$ of the plant extract prepared from shade dried leaves of Hyptis suaveolens That is, immersed for 15 minutes and taken out, washed thoroughly with water, dried the pickled plate in open air.

The weights of the pickled plates were taken using Shimatzu Electronic balance.

Weight of pickled plates, $\mathrm{A}=34.0479 \mathrm{~g}$

Weight of pickled plate, $B=34.3836 \mathrm{~g}$

Weight loss of pickled metal plate, $\mathrm{A}=34.5727-34.0479 \mathrm{~g}=0.5248 \mathrm{~g}$

Weight loss of pickled metal plate, $\mathrm{B}=34.7488-34.3836 \mathrm{~g}=0.3652 \mathrm{~g}$

I.e. without extract, the weight loss of the pickled metal plate, $\mathrm{A}=0.5548 \mathrm{~g}$;

In the presence of plant extract the weight loss of the pickled metal plate, $\mathrm{B}=0.3652 \mathrm{~g}$. From the weight loss, it is clear that the use of plant extract minimizes metal dissolution due to protective film formation. Photographs of pickled plates in acid without and with the HYP extract are given in Fig. 1 and Fig 2 respectively. Striped lines in Fig.2, revealing deposition of active components from the extract on the plate $\mathrm{B}^{7}$

The pickled plates were subjected to polishing before nickel - chrome electroplating. The pickled plates were polished with super quality soap. To get emery finish, the surfaces were smoothened using high speed motor with 120-160 revolutions / s. Plates were cooled using water. Then wire pressed and removed oil by immersing in a bath containing caustic soda and metal cleaning compound. After a dip in $\mathrm{H}_{2} \mathrm{SO}_{4}$ acid bath, the plates were electroplated first with $\mathrm{Ni}$ deposition followed by that of $\mathrm{Cr}$. Both the plates were immersed in the electroplating bath containingNi ${ }^{2+}$ ion solution, carbon and $\mathrm{H}_{2} \mathrm{SO}_{4}$. Electroplated under the conditions were such that:

The $\mathrm{P}^{\mathrm{H}}$ of the bath was 4.5 , Current density is $5 \mathrm{amp}$, Voltage $=50 \mathrm{~V}$ and Timing $=1 \mathrm{~h}$

The nickel plated articles chrome plated by hanging in a bath containing chromium salt and $\mathrm{H}_{2} \mathrm{SO}_{4}$ under the conditions such that:

Current density $-1 \mathrm{amp}$, Voltage $=6 \mathrm{~V}$ and Timing $=1 \mathrm{~min}$

To stabilize the plating, the chrome plated articles were moped using special green composition soap and weights were taken using Shimatzu digital balance. The photo of electroplated plates is given in Fig 3 .

Weight of electroplated plate, $\mathrm{A}=32.7508 \mathrm{~g}$

Weight of electroplated plate, $\mathrm{B}=32.8198 \mathrm{~g}$. 
From the weight loss calculations and shining surface of the electroplated plates (Fig.3),it is clear that there is a cost wise as well as quality wise benefits(with excellent corrosion resistivity) that we can reap on using pickling inhibitors. The probable mechanism explains the role of inhibitor in reducing the metal loss and hydrogen gas evolution.

\subsection{Mechanism of Corrosion Inhibition}

$\mathrm{Fe}+2 \mathrm{HCl} \longrightarrow \mathrm{Fe}^{2+}+\mathrm{H}_{2}+2 \mathrm{Cl}^{-}$

According to equation (1), iron reacts with $\mathrm{HCl}$ with the liberation of hydrogen gas $\left(\mathrm{H}_{2}\right)$.It occurs as long as iron and acid are in contact. The plant extract is the mixture of chemical components such as carbohydrate, protein, alkaloids, flavones, fatty acids, terpene ${ }^{8}$ etc present in the leaves of HYP. All these compounds have functional groups such as- $\mathrm{OH},-\mathrm{NH},-\mathrm{C}=\mathrm{O},-\mathrm{COOH}, \mathrm{C}=\mathrm{C}$, etc. Except $\mathrm{C}=\mathrm{C}$, all other groups have hetero atoms such as $\mathrm{O}$ and $\mathrm{N}$ atoms which have lone pair of electrons. Iron atom or $\mathrm{Fe}^{2+}$ ion (formed in the beginning when the metal and the acid in contact) may react with the functional groups to form complexes ${ }^{9}$. This complexes may deposit and act as a protective film and thus prevent the contact between the metal surface and the acid and thus reduces metal dissolution. The contact between the metal and acid is restricted hence, no reaction involving evolution of hydrogen gas occurs.

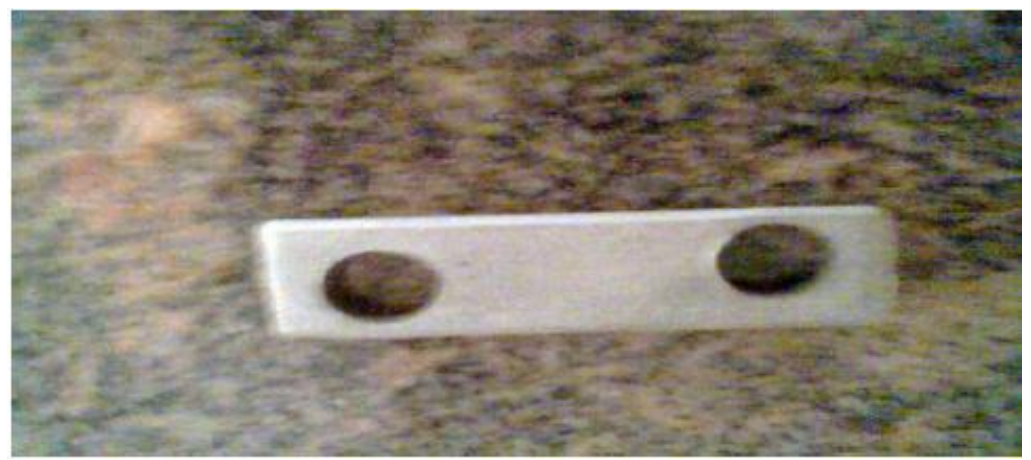

Fig1. Acid pickled plate without plant extract

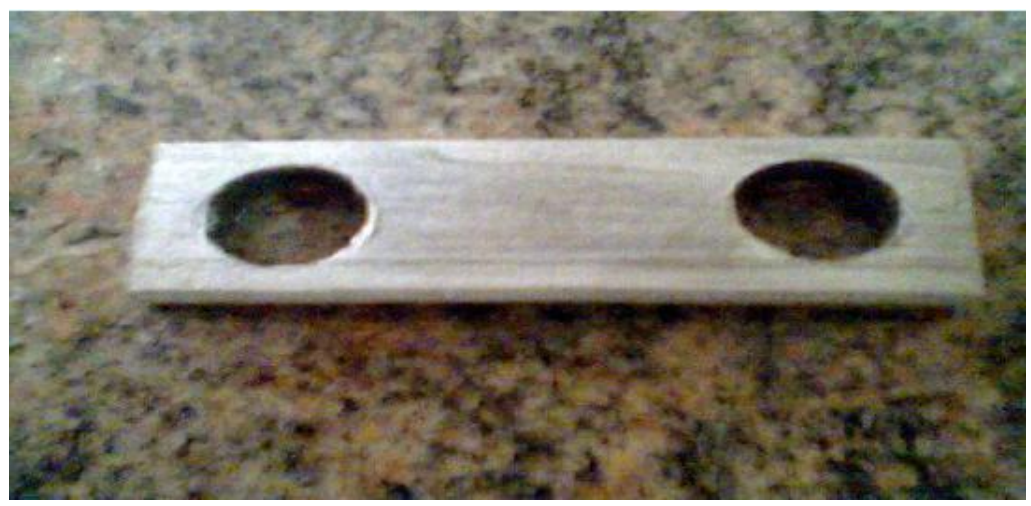

Fig2. Acid pickled plate with plant HYP extract

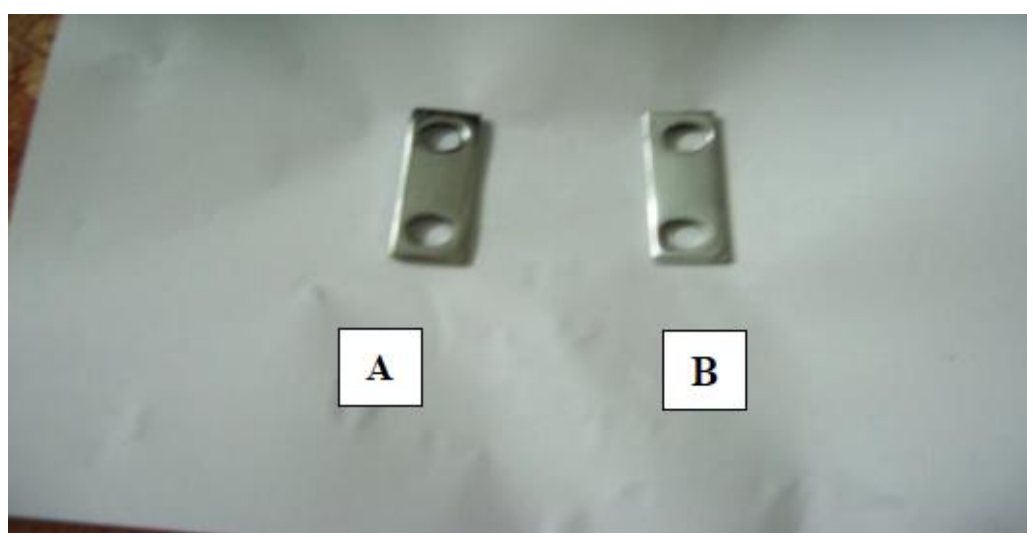

Fig3. Excellent Electroplated Plates - A (acid pickled in the absence of extract)) and -B (acid pickled in presence of plant extract) 


\section{Conclusion}

The leaves extract of HYP is found to be effective in

- Minimizing metal dissolution besides reducing evolution of hydrogen gas.

- Promises excellent electroplating.

\section{REFERENCES}

[1] Fontana, M.G., (1986), Corrosion Engineering, International Students Edition, New York: McGraw-Hill Book.

[2] www.health -hazardous effect of hydrogen gas

[3] Raja, P.B., Rahim, A.A , Osman, H ., Awang,K., Inhibitory effect of Kopsia singapurensis extract on the corrosion behavior of mild steel in acid media,Acta Physico-Chimica Sinica, (2010), 26(8), 2171-2176.

[4] Oguzie E, "Corrosion inhibitive effect and adsorption behaviour of Hibiscus sabdariffa on mild steel in acidic media". Portugaliae Electrochimica Acta 26(3), (2008), pp.303-314

[5] Sanghvi M.J., Shukla S.K., Misra A.N., Padh M.R. and Mehta G.N.,'Inhibition of hydrochloric corrosion of mild steel by acid extracts of Emblica Officianalis and Terminalia Bellirica and Terminalia Chebula", Bulletin of Electrochemistry , 1997, 13, (8-9), 358-361.

[6] Meenakshi R. and.Saratha R, Natural plant extracts as corrosion inhibitors for pickling process in electroplating industries., EO21,regional Science congress, Jointly Organised by The Indian Science Congress Association, Coimbatore Chapter ,12, Dec 15-16.

[7] Meenakshi R. and.Saratha R, "Surface analysis of corrosion inhibited mild steel using SEM technique" ,The Annual National Symposium on Electrochemical Science and Technology, NSEST - 2012,Aug,24-25,2012.

[8] Dipak Koche,Rupali Shirsat, Dyaneshwar Bhadange, Comparative Phytochemical and Nutritional Studies of Leaves and Stem of Three Lamiaceae Members, Research Journal of Pharmaceutical, Biological and Chemical Sciences, (2011), 2 (3), 1-4.

[9] M.A Quraishi, A Singh.,. V.K Singh,. D.K Yadav,. A.K Singh,An approach to corrosion inhibition of mild steel in hydrochloric acid and sulphuric acid solutions by the extract of Murraya koenigii leaves”, Materials chemistry and Physics ,012,22(1), (2010), pp.114-122 . 